\title{
Vaginal cancer in patient presenting with advanced pelvic organ prolapse: case report and literature review
}

\author{
Joseph Kowalski, MD, ${ }^{1}$ Johanna Savage, MD, ${ }^{2}$ Catherine S. Bradley, MD, MSCE ${ }^{1}$
}

Keywords: Vaginal cancer, pelvic organ prolapse, pessaries

\section{Abstract}

Background: Vaginal cancer presenting concurrently with stage 4 uterovaginal prolapse is a rare occurrence, representing less than $1 \%$ of all gynecologic malignancies.

Case: We review the case of an 82-year-old woman who presented for care of prolapse. Examination demonstrated complete uterovaginal prolapse and a vaginal ulcer, later confirmed to be vaginal cancer.

Conclusion: The management of these complicated patients is limited by a lack of data available to guide treatment. This case and the literature review highlight the need for a multidisciplinary approach to treatment and a high level of clinical suspicion for diagnosis of these very challenging cases.

${ }^{1}$ University of lowa Hospitals and Clinics, Department of Obstetrics and Gynecology, lowa City, lowa

${ }^{2}$ University of lowa Hospitals and Clinics, Department of Pathology, lowa City, lowa

\section{Introduction}

Primary vaginal carcinomas are extremely rare, accounting for only about $1 \%$ of all gynecologic malignancies. ${ }^{1}$ At the time of diagnosis, patients are typically in their 6th or 7th decade of life and most commonly present with vaginal bleeding from a lesion localized to the upper third of the vagina. There are currently no specific guidelines for treatment of vaginal cancer due to the paucity of available data. However, certain cases of early stage disease may be treated with primary surgery. Advanced disease is generally treated with chemoradiation or radiation alone. ${ }^{1}$

The incidence of symptomatic prolapse and prolapse surgery increases with age. Women older than 80 years are the fastest growing segment of the population. $^{2,3}$ However, primary vaginal

Please cite this paper as: Kowalski J, Savage J, Bradley CS. Vaginal cancer in patient presenting with advanced pelvic organ prolapse: case report and literature review. Proceedings in Obstetrics and Gynecology, 2015;5(1):Article 3 [ 8 p.]. Available from: http://ir.uiowa.edu/pog/ Free full text article.

Corresponding author: Joseph Kowalski, Fellow, Department of Obstetrics and Gynecology, University of lowa Hospitals and Clinics, 200 Hawkins Drive, lowa City, IA 52242-1080, USA. Telephone: 319-356-1616, Fax: 319-3848620. Email: joseph-kowalski@uiowa.edu

Financial Disclosure: The authors report no conflict of interest.

Received: 21 January 2015; received in revised form: 26 March 2015; accepted 6 May 2015; POG in Press, 6 May 2015

Copyright: (c) 2015 Kowalski et al. This is an open-access article distributed under the terms of the Creative Commons Attribution License, which permits unrestricted use, distribution, and reproduction in any medium, provided the original author and source are credited. 
carcinomas are rare. A primary vaginal carcinoma presenting in conjunction with stage IV uterovaginal prolapse is an even rarer phenomenon. The reported incidence of prolapse from referral centers range from $13.6 \%$ to $16.3 \%$ of patients with primary vaginal cancer., 4 A comprehensive review of the available English language literature reveals only 7 case reports and 1 case series (6 patients) of primary vaginal cancer associated with pelvic organ prolapse (Table 1). ${ }^{4,6-12}$ Conversely, finding an erosion of the vaginal mucosa in a postmenopausal woman in the setting of treatment for pelvic organ prolapse is not uncommon. This finding may be present with or without the use of a vaginal pessary and warrants very close monitoring.

We will describe the case of a patient referred for management of pelvic organ prolapse who was found to have vaginal cancer. We will also review all other English language reports of prolapse complicated by vaginal cancer with an emphasis on the unique challenges of diagnosis and management that this situation presents.

\section{Case Report}

An 82-year-old G6P6 female was referred to our institution for further management of uterovaginal prolapse. A year prior, she had been evaluated at an outside institution and declined surgical management or the use of a pessary for treatment of her prolapse. Her primary presenting complaints were progressively worsening vaginal pressure, incomplete bladder emptying, occasional urinary incontinence and a newly recognized "crack" in the prolapsed tissue of 2 weeks duration.
She had no known oncologic history and had no history of abnormal Pap smears. Her last normal Pap smear had been approximately one year prior to initial presentation. Her medical history was significant for atrial fibrillation, hypertension and a remote history of right salpingo-oophorectomy for unknown reasons. She had never smoked. Physical examination in the office revealed complete, irreducible uterovaginal prolapse that was moderately tender. There was a 4 by 5 $\mathrm{cm}$. indurated, ulcerated, foul-smelling vaginal lesion remote in location from the cervix. The lesion had a grey, necrotic-appearing base, and it appeared to track about $2 \mathrm{~cm}$. into the left vaginal sidewall (Figure 1). Her POP-Q exam included: $\mathrm{Aa}+3, \mathrm{Ba}+12$, $\mathrm{C}+12, \mathrm{D}+12, \mathrm{Bp}+12$, and $\mathrm{Ap}+3 . \mathrm{GH}$. $\mathrm{PB}$ and TVL were not able to be assessed.

The patient was directly admitted to the urogynecology service from clinic and started on intravenous antibiotic therapy. She was taken to the operating room with the assistance of the gynecologic oncology service for vaginal biopsies and cystoscopy as well as wound irrigation and debridement. The prolapse was able to be successfully reduced in the operating room. Intraoperative observations were significant for left paravaginal nodularity and tethering of the ulcerated area to the paravaginal tissue. Cystoscopy was unremarkable. A rectal exam was unremarkable with the exception of mild prolapse of the rectal mucosa. Histopathology of the vaginal biopsies demonstrated moderately differentiated squamous cell carcinoma with perineural invasion (Figure 2) 

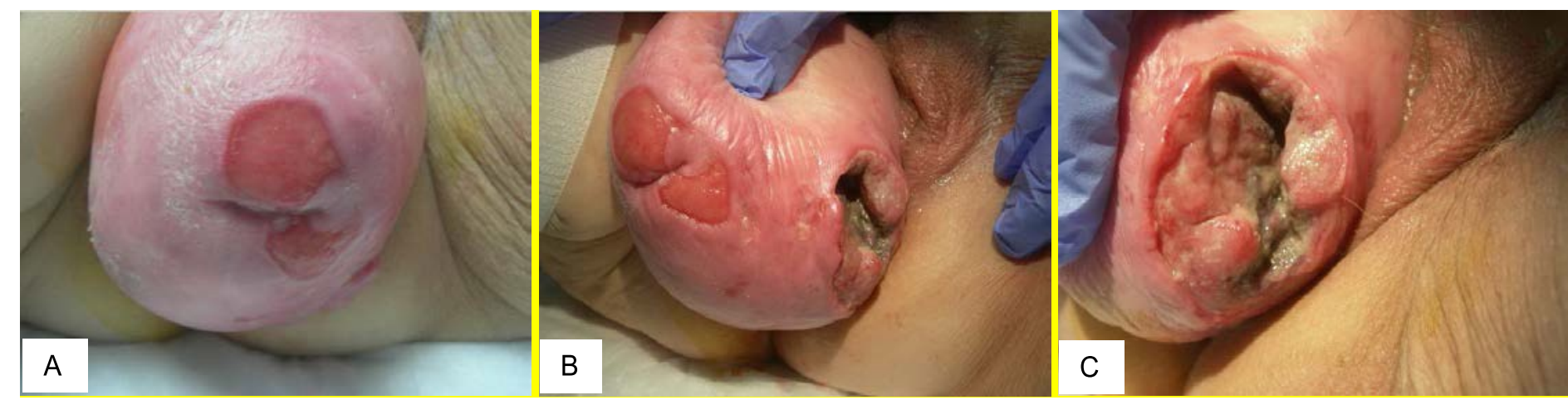

Figure 1. Complete uterovaginal prolapse with a well-defined ulcer on the left vaginal side-wall (A-C).
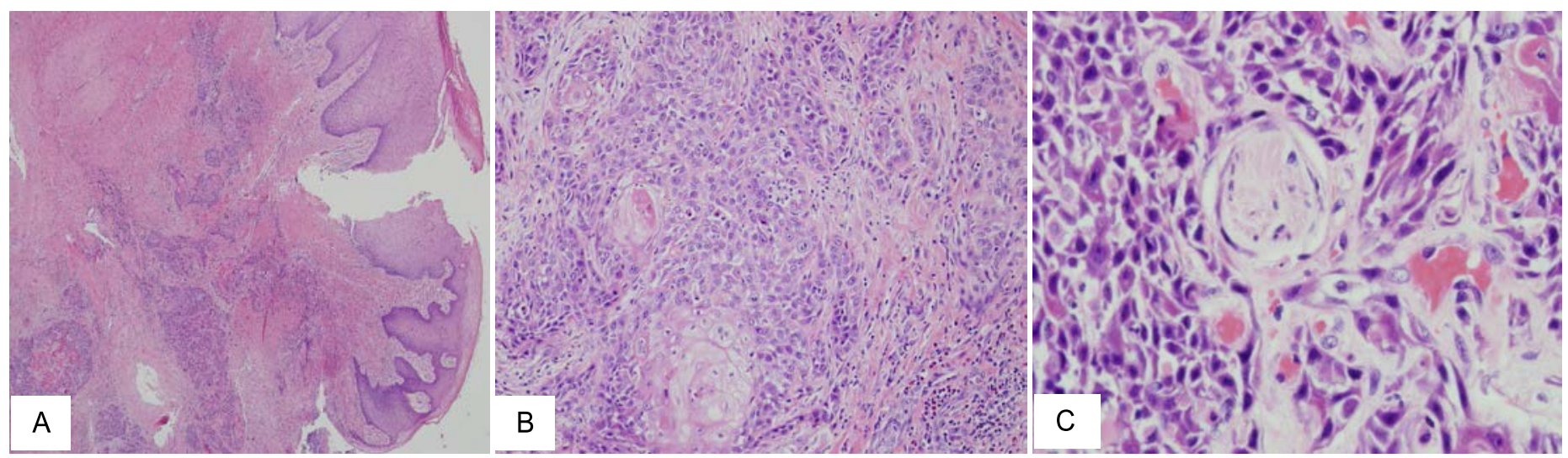

Figure 2. Histopathology of the vaginal biopsies demonstrating moderately differentiated squamous cell carcinoma (A-C) with focal perineural invasion (C). 
Table 1. Publications reporting vaginal carcinoma complicated by concurrent pelvic organ prolapse.

\begin{tabular}{|c|c|c|c|c|c|c|}
\hline Author & Year & Title & $\begin{array}{l}\text { Prolapse } \\
\text { Stage* }\end{array}$ & FIGO Stage & Treatment & Comments \\
\hline Berthelsen $^{6}$ & 1957 & $\begin{array}{l}\text { Vaginal carcinoma associated } \\
\text { with total prolapse }\end{array}$ & $4^{* *}$ & Not reported & $\begin{array}{l}\text { Vaginal hysterectomy and } \\
\text { vaginectomy. }\end{array}$ & No follow up reported. \\
\hline Howat $^{7}$ & 1984 & $\begin{array}{l}\text { Carcinoma of the vagina } \\
\text { presenting as a ruptured } \\
\text { procidentia with an entero-vaginal } \\
\text { fistula and prolapse of the small } \\
\text { bowel }\end{array}$ & $4 * *$ & Not reported & $\begin{array}{l}\text { Total abdominal hysterectomy } \\
\text { and bilateral salpingo- } \\
\text { oophorectomy and vaginal } \\
\text { biopsies taken. } 15 \mathrm{~cm} \text { small } \\
\text { bowel resection with end-to-end } \\
\text { anastomosis followed by } \\
\text { radiotherapy. }\end{array}$ & No follow up reported. \\
\hline $\mathrm{Rao}^{4}$ & 1986 & $\begin{array}{l}\text { Primary carcinoma of vagina with } \\
\text { uterine prolapse }\end{array}$ & 3 (all cases) & Not reported & $\begin{array}{l}5 \text { patients underwent external } \\
\text { beam radiation only. } 1 \text { patient } \\
\text { refused treatment. }\end{array}$ & $\begin{array}{l}\text { Case series included } 6 \text { patients. } 2 \text { patients } \\
\text { with irreducible prolapse. } 2 \text { patients } \\
\text { developed vesicovaginal fistula after } \\
\text { radiation. } 1 \text { recurrence and } 1 \text { fatality } \\
\text { reported. }\end{array}$ \\
\hline Iavazzo $^{8}$ & 2007 & $\begin{array}{l}\text { Vagina carcinoma in a completely } \\
\text { prolapsed uterus. A case report }\end{array}$ & 3 & 1 & $\begin{array}{l}\text { Radical vaginal hysterectomy } \\
\text { with excision of the upper two- } \\
\text { thirds of the vagina followed by } \\
5400 \text { cGy external beam } \\
\text { radiation. }\end{array}$ & No recurrence during 3.5 years follow up. \\
\hline Gupta $^{9}$ & 2007 & $\begin{array}{l}\text { A rare case of primary invasive } \\
\text { carcinoma of vagina associated } \\
\text { with irreducible third degree } \\
\text { uterovaginal prolapse }\end{array}$ & 3 & 3 & $\begin{array}{l}\text { Chemoradiation with 5- } \\
\text { fluorouracil and carboplatin }\end{array}$ & $\begin{array}{l}\text { Irreducible. Reported clinical improvement } \\
\text { and reduction in size of invasive growth. } \\
\text { Length of follow up not specified. }\end{array}$ \\
\hline Ghosh $^{10}$ & 2008 & $\begin{array}{l}\text { Primary invasive carcinoma of } \\
\text { vagina with third degree } \\
\text { uterovaginal prolapse: a case } \\
\text { report and review of literature }\end{array}$ & 3 & 1 & $\begin{array}{l}\text { Radical vaginal hysterectomy } \\
\text { with bilateral extraperitoneal } \\
\text { pelvic lymphadenectomy }\end{array}$ & No recurrence during 12 months follow up. \\
\hline
\end{tabular}


Proceedings in Obstetrics and Gynecology, 2015;5(1):3

Batista $^{11}$

2009 Uterine prolapse complicated by vaginal cancer: A case report and

literature review

Wang $^{12}$

2014 A rare case of invasive vaginal "Third carcinoma associated with vaginal degree” prolapse
Not reported

(1)

1
Partial transvaginal colpectomy No recurrence during 24 months follow up. followed by 5040 cGy external

beam radiation.

Vaginal hysterectomy, “apex No recurrence during 4 years follow up. fixation”, anterior/posterior colporrhaphy and partial vaginectomy followed by 5040 cGy external beam radiation.

* The method used to stage prolapse in these reports was not specified.

** Prolapse was described as, "total prolapse," in the Berthelsen report and as, "complete procidentia," in the Howat report.

Given the diagnosis of vaginal squamous cell carcinoma, imaging studies were performed for clinical staging. A positron emission tomography/computed tomography (PET/CT) scan demonstrated hypermetabolic foci in the vaginal wall, sigmoid colon, rectum and pelvic and periaortic lymph nodes. A colonoscopy, obtained because of heme-positive stool, demonstrated a nearly circumferential mass $15 \mathrm{~cm}$. from the anal verge. Histopathology of the colonic mass demonstrated moderately differentiated adenocarcinoma. The patient was subsequently evaluated by surgical oncology, radiation oncology and medical oncology. She completed external beam radiation (4500 cGy) and cisplatin (3 cycles, $40 \mathrm{mg} / \mathrm{m} 2$ ) with a number of unscheduled interruptions due to medical complications and a decline in her performance status. Following the completion of chemoradiation, she underwent evaluation to consider palliative vaginal hysterectomy with colpocleisis. However, her medical condition rapidly deteriorated precluding any further surgery. She was admitted to an inpatient hospice facility and expired shortly thereafter,

Vaginal cancer with advanced pelvic organ prolapse about 4 months after initial presentation to our institution. The precise cause of death is unknown to us.

\section{Comment}

Advanced uterovaginal prolapse presenting with a previously unrecognized primary vaginal carcinoma is a rare occurrence. In this patient, the finding of a secondary tumor - a concurrent colorectal adenocarcinoma - presented further complexity. This case serves to highlight several important points, including the importance of careful evaluation of vaginal erosions or lesions in patients presenting with pelvic organ prolapse. Vaginal wall erosions and ulcerations frequently occur in patients with severe pelvic organ prolapse, although the true incidence of these complications is not well-described. Such patients are often at risk for vaginal wall erosions due to menopauseassociated vaginal atrophy. Mechanical irritation from urine leakage, pads and undergarments is not uncommon and results in superficial skin breakdown. 
Pessary use may also put the patient at further risk for vaginal erosion. To our knowledge, there are no published guidelines for the management of vaginal erosions or ulcerations associated with or without pessary use. However, mild vaginal erosions may be conservatively treated with vaginal estrogen, careful vulvar-vaginal skin care, treatment of urinary incontinence and removal of any inciting source of injury, such as a pessary. Any erosion that does not resolve with conservative treatment within one month should be biopsied. ${ }^{13}$ Consideration should be given to immediate biopsy for any lesion with concerning characteristics, such as active bleeding, foul smell or an associated solid mass. We performed a review of the English language literature relating to vaginal cancer and concurrent pelvic organ prolapse (Table 1). Our patient had stage 4 prolapse based on both the Baden-Walker and POP-Q classification systems. All of the previously reported cases had stage 3 or 4 prolapse. POP-Q scores were not available in the previously reported cases. Three of the previously reported cases were noted to have irreducible prolapse. Our patient had irreducible prolapse when initially examined in the office. The prolapse was only able to be reduced when the patient was under general anesthesia in the operating room. Therefore, prolapse with concurrent ulceration that is unable to be reduced on exam should cause an elevated index of suspicion for an associated mass or malignancy.

This patient presented with clinical stage $4 \mathrm{~B}$ vaginal carcinoma and was treated with primary chemoradiation. The $\mathrm{PET} / \mathrm{CT}$ findings cannot be attributed to the vaginal carcinoma with absolute certainty since she had a concurrent primary cancer. However, the evidence of lymph node metastasis was presumed to be due to the vaginal carcinoma. No clear guidelines presently exist to guide clinicians in the treatment of vaginal carcinoma, especially in the presence of significant pelvic organ prolapse. Typically, the stage of disease and assessment of the patient's medical comorbidities determine the aggressiveness of therapy. Stage I and early stage II cancers limited to the upper vagina in a medically fit patient may be adequately treated with surgical excision alone in select circumstances. Stage III and IV vaginal cancers are generally treated with external beam radiation with or without brachytherapy. Cisplatin can be used as a radiation sensitizer in the same manner that it is typically used in the treatment of advanced cervical cancer.

In cases of vaginal cancer presenting with significant prolapse there are additional considerations during treatment planning. Most importantly, the bladder and any contents of an enterocele sac will have more exposure to the radiation field in these patients. Of note, two of the six patients described in Rao's 1984 case series developed vesicovaginal fistulas following primary radiation treatment. ${ }^{4}$ Furthermore, brachytherapy may not be technically feasible without prior surgery to reduce the prolapse. Performing a palliative vaginal hysterectomy or colpocleisis prior to radiation treatment is an additional consideration. This treatment approach may limit the risk of urologic complications due to reducing exposure 
of the bladder to the radiation field. However, surgery and the necessary recovery period prior to radiation may delay treatment of the cancer. The performance status of the individual patient must be taken into consideration as well. Alternatively, a palliative surgery to address the prolapse may be undertaken following radiation treatment. There are no recommendations in the literature to guide this particular treatment decision.

This case highlights the importance of careful evaluation of vaginal erosions in the setting of pelvic organ prolapse and pessary use. In the absence of welldefined treatment protocols for vaginal cancer with concurrent prolapse, this case also illustrates the importance of a multidisciplinary approach involving urogynecology, gynecologic oncology, surgical oncology, radiation oncology and medical oncology.

\section{References}

1. National Cancer Institute: General information about vaginal cancer. 2011. Available at: http://www.cancer.gov/cancertopics/pdq/ treatment/vaginal/HealthProfessional Accessed October 25, 2011

2. Barber MD, Maher C. Epidemiology and outcome assessment of pelvic organ prolapse. Int Urogynecol J. 2013 Nov;24(11):1783-90. doi: 10.1007/s00192-013-2169-9. PubMed PMID: 24142054.

3. Luber KM, Boero S, Choe JY. The demographics of pelvic floor disorders: current observations and future projections. Am J Obstet Gynecol. 2001 Jun;184(7):1496-501; discussion 15013. http://dx.doi.org/10.1067/mob.2001.114 868. PubMed PMID: 11408873.
4. Rao K, Kumar NP, Geetha AS. Primary carcinoma of vagina with uterine prolapse. J Indian Med Assoc. 1989 Jan;87(1):10-2. PubMed PMID: 2754264.

5. Kaiser $\mathrm{IH}$. Primary carcinoma of the vagina. Cancer. 1952 Nov;5(6):1146-60. http://dx.doi.org/10.1002/10970142(195211)5:6<1146::AIDCNCR2820050611>3.0.CO;2-3 PubMed PMID: 12998021.

6. Berthelsen HG. Vaginal carcinoma associated with total prolapse; report of a case. Acta Obstet Gynecol Scand. 1957;36(2):257-61.

http://dx.doi.org/10.3109/000163457091 57412 PubMed PMID: 13434883.

7. Howat JM, Stassan L, Mohandas I, Daw E. Carcinoma of the vagina presenting as a ruptured procidentia with an enterovaginal fistula and prolapse of the small bowel. Postgrad Med J. 1984 Jun;60(704):435-6. http://dx.doi.org/10.1136/pgmj.60.704.43 5 PubMed PMID: 6462989.

8. Iavazzo C, Vorgias G, Vecchini G, Katsoulis $M$, Akrivos $T$. Vaginal carcinoma in a completely prolapsed uterus. A case report. Arch Gynecol Obstet. 2007 Jun;275(6):503-5. Epub $2006 \quad$ Nov 23 http://dx.doi.org/10.1007/s00404-0060284-2 PubMed PMID: 17123094.

9. Gupta N, Mittal S, Dalmia S, Misra R. A rare case of primary invasive carcinoma of vagina associated with irreducible third degree uterovaginal prolapse. Arch Gynecol Obstet. 2007 Nov;276(5):5634. Epub 2007 Jul 13. http://dx.doi.org/10.1007/s00404-0070415-4 PubMed PMID: 17628814. 
10. Ghosh SB, Tripathi R, Mala YM, Khurana N. Primary invasive carcinoma of vagina with third degree uterovaginal prolapse: a case report and review of literature. Arch Gynecol Obstet. 2009 Jan;279(1):91-3. doi: 10.1007/s00404008-0815-0. Epub 2008 Oct 21. PubMed PMID: 18936946.

11. Batista TP, Morais JA, Reis TJ, Macedo $\mathrm{FI}$. A rare case of invasive vaginal carcinoma associated with vaginal prolapse. Arch Gynecol Obstet. 2009 Nov;280(5):845-8. doi: 10.1007/s00404009-1016-1. Epub 2009 Mar 5. PubMed PMID: 19263061.

12. Wang $\mathrm{Y}$, Li Q, Du H, Lv S, Liu H. Uterine prolapse complicated by vaginal cancer: a case report and literature review. Gynecol Obstet Invest. 2014;77(2):141-4. doi: 10.1159/000357566. Epub 2014 Jan 23. PubMed PMID: 24481208.

13. O'Dell K, Atnip S. Pessary care: follow up and management of complications. Urol Nurs. 2012 May-Jun;32(3):126-36, 145; quiz 137. PubMed PMID: 22860391. 